\section{CME: Practical solutions to the antibiotic resistance crisis}

Approximately 700000 people die annually from antibiotic-resistant infections worldwide, and this will rise to 10 million per year by 2050 if our current overuse and misuse of antibiotics is not curtailed. Moreover, if antibiotics are lost, each and every medical procedure that relies on antibiotics to prevent or treat infection will be affected, changing the face of modern medicine as we know it. Far from being a futuristic fantasy, this is already being played out in South African hospitals, leading to closure of wards, cancellation of operating lists, and patients being sent home without operations that they need because of colonisation with multidrug- or pandrug-resistant bacteria. Welcome to the postantibiotic era!

This edition of CME focuses on the practical measures that we can take to make antibiotic prescribing appropriate and what needs to be done to prevent infection in the first place, thereby negating their need. These interventions, along with heightened surveillance and reporting of resistance patterns and antibiotic usage, form the battle strategy to defend the efficacy of antibiotics. The antibiotic pipeline, which in terms of new classes of antibiotic has been dry for the past 28 years and for antibiotics against Gram-negative infections is not projected to yield a new antibiotic for the next 10 - 15 years, cannot be relied on to save the day. On the contrary, no antibiotic has lasted more than 16 years without resistance developing to it. The emphasis is therefore on preserving what we have through antibiotic stewardship, an intervention that ensures appropriate, optimal antibiotic prescribing, without doing harm to the patient.

\section{SAMJ: Antimicrobial resistance}

Ninety years ago, having just discovered penicillin, Alexander Fleming fretted about antimicrobial resistance (AMR). His concerns were well founded - last year, the World Health Organization (WHO) declared that AMR 'threatens the achievements of modern medicine. A post-antibiotic era - in which common infections and minor injuries can kill - is a very real possibility for the 21st century. $^{\text {'[1] }}$ As will be appreciated, some clinical isolates of Mycobacterium tuberculosis, Neisseria gonorrhoeae, Enterococcus faecium, Staphylococcus aureus, Klebsiella pneumoniae, Acinetobacter baumannii and Pseudomonas aeruginosa, and species of Enterobacter, Salmonella and Shigella, are now resistant to most antibiotics. ${ }^{[2]}$

Antibiotics are used around the world in livestock and fish farming, often in crowded,

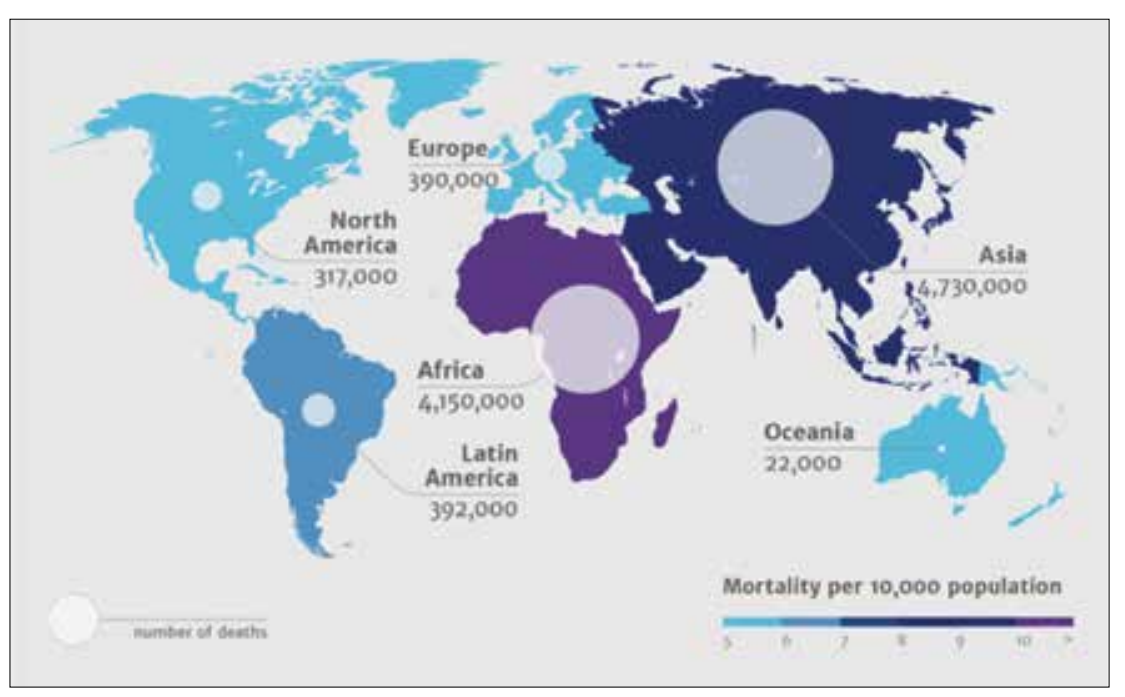

Fig. 1. Deaths attributable to antimicrobial resistance every year by 2050. ${ }^{[4]}$

unclean conditions, to facilitate faster growth and guarantee a cheap food supply. Resistant bacteria can be transferred to humans through contact with livestock, through the food chain, and through waste water from these operations, as well as via wastewater from hospitals and pharmaceutical plants. ${ }^{[3]}$

By 2050, it is reckoned, over 4 million deaths in Africa will be attributable to AMR (Fig. 1). ${ }^{[4]}$

Since 1987 there has been a relative 'discovery void', with only 12 new antibiotics approved since 2000. ${ }^{[5]}$ Because the development of antibiotics, from discovery to human trials, is difficult and expensive, the current stock of antibiotics needs to be conserved and any new ones preserved. Last year the Glaxo CEO stated that pharma was unlikely to spend research funds on discovery of new antibiotics if they were to sit on the shelf for fear of development of AMR upon their use. Fortunately, 'several small companies, seeking to fill the gap, have had new antibiotics approved, and the world's fourth-largest drug company recently announced its return to the effort. However, major disincentives remain, including the difficulty of conducting large clinical trials to compare drugs in patients with antibioticresistant infections.'[2]

In May this year, the World Health Assembly debates the international response to the AMR crisis, namely a Global Action Plan (GAP) for AMR. ${ }^{[6]}$ Adoption of the GAP will follow a year of consultation between a tripartite alliance (comprising the WHO, the Food and Agriculture Organization (FAO) and the World Organization for Animals (OIE)) with governments and all relevant stakeholders.

In this issue of $S A M J$ we emphasise the crisis of AMR, and seek to warn against administering antibiotics simply because we are unsure of a diagnosis or to satisfy patient demand, especially when the infection may be viral and not bacterial. This is why we are pleased to offer the Working Group of the Infectious Diseases Society of Southern Africa's updated recommendations for the management of upper respiratory tract infections in South Africa, ${ }^{[7]}$ and devote this month's CME to antibiotic stewardship.

In this regard, two editorials are key reading ${ }^{[8,9]}$ as is the research article by McKay et $a .^{[10]}$ on community- versus healthcareacquired bloodstream infections at Groote Schuur Hospital, Cape Town, ${ }^{[10]}$ in which local surveillance data are used to support empirical choices of antimicrobials following assessment of whether the infection is community or healthcare acquired. As the Lowman editorial ${ }^{[8]}$ confirms, 'good ol' cloxacillin (a far superior drug to vancomycin in the treatment of $S$. aureus) is still a perfectly suitable option in the right patient. Similarly, with a $<5 \%$ ESBL rate for Enterobacteriaceae associated with community-acquired BSIs, the third- and fourth-generation cephalosporins still have an important role to play.

\section{Diabetes in children}

For children with type 1 diabetes, certain fundamental behaviours are associated with better glycaemic control: frequency of blood glucose (BG) testing (requiring sufficient $B G$ test strips), frequency of insulin injections, absence of insulin omission, adherence to meal planning, and patient-initiated dose adjustments, based on BG testing. Three articles ${ }^{[1-13]}$ deal with management of diabetes in children and point out the sharp contrast between the status of patients in the public and private sectors. In the public sector children often cope without adult assistance and, lacking a sufficiency of BG test strips, are unable 
to undertake any more than rudimentary BG monitoring; in the private sector they receive education and dietary and exercise advice and have access to the most up-to-date management techniques. Davey and Segal ${ }^{[13]}$ insist that restricted access to BG test strips - so often the case in the public sector - should not be allowed to handicap any patient's diabetes control efforts.

\section{The simple bread tag - a menace to society}

Karro et al. ${ }^{[14]}$ alert us to the dangers of the small rectangle of jagged plastic securing the bag containing a loaf of sliced bread. Three infants in whom a bread tag had lodged in the laryx or subglottis had to be rescued by bronchoscopy. Made of thin plastic, the tags tend to be radiolucent on $\mathrm{X}$-ray and may even be missed on both flexible nasopharyngoscopy and direct laryngoscopy. The authors advise that until redesigned in a safer format, the tags should be removed from the bag of bread and stored out of reach of young children, or donated to Bread Tags for Wheelchairs The Wheelchair Foundation, ${ }^{[15]}$ which recycles them to buy wheelchairs.

\section{Idiopathic thrombocytopenic purpura (ITP)}

First-line treatment of ITP is with oral glucocorticoids, with splenectomy employed as second-line treatment. Newer drugs such as rituximab and thrombopoeitin agonists have brought the role of splenectomy into question, particularly as a lethal late complication may be postsplenectomy sepsis. Antel et al. ${ }^{[16]}$ in their article 'Role of splenectomy for immune thrombocytopenic purpura (ITP) in the era of new second-line therapies and in the setting of a high prevalence of HIV-associated ITP' confirm that splenectomy should remain the second-line treatment for ITP in most patients, including those with HIV-associated ITP.

\section{Ocular surface squamous neoplasia}

Emerging evidence suggests that ocular surface squamous neoplasia (OSSN) that requires surgery may be emerging as an AIDS-defining illness in sub-Saharan Africa. A study of OSSN among HIV-infected patients in Botswana ${ }^{[17]}$ shows that the annual incidence of OSSN increased significantly from 3 cases per 100000 in 1998 to 7/100 000 in 2004. The authors report on some 500 patients, more than half of whom had AIDS (CD4 counts $<200$ cells $/ \mu \mathrm{L}$ ).

\section{JS}

1. Antimicrobial resistance: Global report on surveillance 2014. www.who.int/iris/.../9789241564748 eng.pdf (accessed 23 March 2015).

2. Nathan C, Cars O. Antibiotic resistance - problems, progress, and prospects. N Engl J Med 2014;371:1761-1763. [http://dx.doi.org/10.1056/NEJMp1408040]

3. The dangers of hubris on human health. http://reports.weforum.org/global-risks-2013/risk-case-1/ the-dangers-of-hubris-on-human-health (accessed 23 March 2015).

4. Review on Antimicrobial Resistance. http://amr-review.org/sites/default/files/AMR\%20Review\%20

Review on Antimicrobial Resistance. http://amr-review.org/sites/default/files/AMR\%20Review $\% 20$
Paper\%20-\%20Tackling\%20a\%20crisis\%20for\%20the\%20health\%20and\%20wealth\%20of $\% 20$ Paper\%20-\%20Tackling\%20 \% 20 crisi $\% 2$
nations_1.pdf (accessed 15 April 2015).

nations_l.pdf (accessed 15 April 2015).
5. Frontier Pharma: Antibiotics - identifying and commercializing first-in-class innovation. http:// 5. Frontier Pharma: Antibiotics - identifying and commercializing first-in-class innovation. http://
gbiresearch.com/report-store/market-reports/frontier-pharma/frontier-pharma-antibioticsidentifying-and-commercializing-firstinclass-innovation (accessed 23 March 2015)

6. Mendelson M, Matsoso P. The World Health Organization Global Action Plan for antimicrobial resistance. S Afr Med J 2015;105(5):325. [http://dx.doi.org/10.7196/SAMJ.9644]

7. Brink AJ, Cotton MF, Feldman C, et al. Updated recommendations for the management of upper respirator tract infections in South Africa. S Afr Med J 2015;105(5):345-352. [http://dx.doi.org/10.7196/SAMJ.8716]

8. Lowman W. Key to antimicrobial stewardship success: Surveillance by diagnostic microbiology laboratories. S Afr Med J 2015;105(5):359-360. [http://dx.doi.org/10.7196/SAMJ.9615]

9. Mer M, Lipman J. Antibiotic administration in the critically ill - in need of intensive care! S Afr Med J 2015;105(5):357-359. [http://dx.doi.org/10.7196/SAMJ.9665]

10. McKay R, Bamford C. Community- versus healthcare-acquired bloodstream infections at Groote Schuur Hospital, Cape Town, South Africa. S Afr Med J 2015;105(5):363-369. [http://dx.doi. org/10.7196/SAMJ.8183]

11. De Villiers FPR. The poor children of the poor: Coping with diabetes control in a resource-poor setting. S Afr Med J 2015;105(5):397-399. [http://dx.doi.org/10.7196/SAMJ.8496]

12. Kalweit KL, Briers N, Olorunju SAS. The success of various management techniques used in South African children with type 1 diabetes mellitus. S Afr Med J 2015;105(5):400-404. [http://dx.doi org/10.7196/SAMJ.9334]

13. Davey B, Segal DG. Self-monitoring of blood glucose measurements and glycaemic control in a managed care paediatric type 1 diabetes practice. S Afr Med J 2015;105(5):405-407. [http://dx.doi. org/10.7196/SAMJ.7686]

14. Karro R, Goussard P, Loock J, Gie R. The simple bread tag - a menace to society. S Afr Med 2015;105(5):342-344. [http://dx.doi.org/10.7196/SAMJ.8996]

5. Bread Tags for Wheelchairs - the Wheelchair Foundation. http://wheelchairfoundation.org/blog/ breadtags-for-wheelchairs/ (accessed 16 April 2015).

16. Antel KR, Panieri E, Novitzky N. Role of splenectomy for immune thrombocytopenic purpura (ITP) in the of of $\mathrm{E}$, Noving $\mathrm{N}$. Role of sploctomy for mmune thro in the era of new second-line therapies and in the setting of a high preval
Afr Med J 2015;105(5):408-412. [http://dx.doi.org/10.7196/SAMJ.8987]

Afr Med J 2015;105(5):408-412. [http://dx.doi.org/10.7196/SAM).8987] 17. Steele KT, Steenhoff AP, Bisson GP, Nkomazana O. Ocular surface squamous neoplasia among HIV-
infected patients in Botswana. S Afr Med J 2015;105(5):379-383. [http://dx.doi.org/10.7196/SAMJ.8524]

\section{This month in the $S A M J$...}

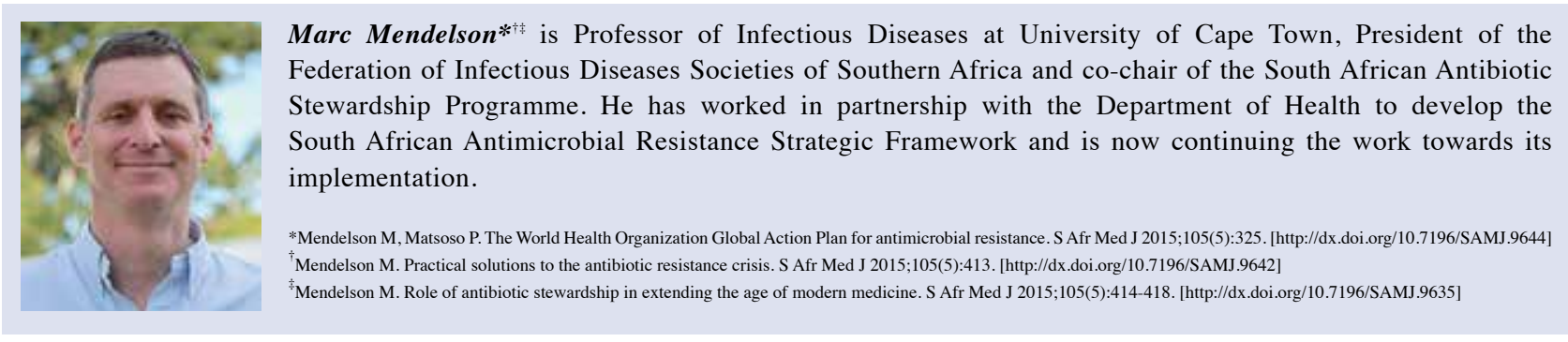

Warren Lowman* is a clinical microbiologist with Vermaak and Partners Pathologists. He also holds an honorary lecturer's post in the Department of Clinical Microbiology and Infectious Diseases at the University of the Witwatersrand and is a consultant clinical microbiologist at the Wits Donald Gordon Medical Centre. He is a current Exco member of the South African Society of Clinical Microbiology (SASCM) and chairs two subcommittees within SASCM. He serves in an advisory capacity to a number of other national clinical microbiology-related committees and is driven by the need to improve the clinical application and integration of microbiological diagnostic services in medical care. This guides his interests in hospital-related clinical microbiology, which span many facets from infection prevention and control to antimicrobial susceptibility testing to antimicrobial therapeutics. He believes that his passion for 'bugs' is dwarfed only by the scope and complexity of the microbial world, which ensures that there is never a dull moment.

*Lowman W. Key to antimicrobial stewardship success: Surveillance by diagnostic microbiology laboratories. S Afr Med J 2015;105(5):359-360. [http://dx.doi.org/10.7196/SAMJ.9615]

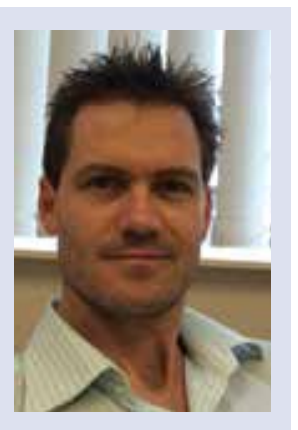

